\title{
O TABULEIRO DAS (IM)PERTINÊNCIAS CIÊNCIAS HUMANAS E CIÊNCIAS DE DADOS: APROXIMAÇÕES*
}

O pequeno livrinho que lhes apresentamos é uma das manifestações da força da natureza, porque desafia as probabilidades de vir a ser possível, de vir a ser pertinente e, por isso, talvez, para alguns, é uma obra da (im)pertinência. Então, deixamos o convite para uma leitura que se pode agarrar por qualquer ponto, qualquer lugar (do meio para o fim, do fim para o começo).

Os textos que se encontram aqui reunidos originam-se das apresentações e diálogos dos respectivos autores durante o Seminário Ciência, Politicas e Metodologias de Pesquisa: diálogos Brasil e Portugal', ocorrido nos dias 07 e 08 dezembro de 2017, nas instalações do Núcleo ETC da Universidade Federal de São Carlos (UFSCar), em Sorocaba. O referido evento contou com apoio financeiro da Capes (Coordenação de Aperfeiçoamento de Pessoal de Nível Superior) e teve por objetivo tratar de questões relacionadas às pesquisas em Ciências Humanas e sua colaboração na análise e elaboração de políticas públicas, assim como os desafios e conquistas metodológicas de integração entre essa área e a utilização de dados armazenados, produzidos e sistematizados em meios digitais. Pretendia-se contribuir, também, com o debate público sobre metodologias qualitativas e/ou quantitativas e suas implicações políticas e científicas na produção de sentido na perspectiva interdisciplinar.

Assim, o Seminário promoveu o diálogo entre pesquisadoras e pesquisadores brasileiros do Núcleo de Estudos e Pesquisas em Tecnologia (NEPeTeCS) e da Linha de Pesquisa em "Educação, Comunidade e Movimentos Sociais - do Programa de Pós-Graduação em Educação da UFSCar; do Mestrado em Comunicação do Programa de Pós-Graduação em Comunicação (PPGCOM) da Faculdade de Informação e Comunicação (FIC), e do Laboratório de Políticas Públicas Participativas (L3P)

\footnotetext{
*DOI- 10.29388/978-65-86678-33-8-0-f.9-14

${ }^{1}$ As falas, transformadas em texto, estão disponíveis em < https://www.youtube.com/ channel/UCP14PffMrZOG9rZkXS4C0 g/videos>, Acesso em: 10 out. 2020.
} 
da Universidade Federal de Goiás (UFG); do Grupo de Pesquisa COMUNICA da Universidade Federal de São Carlos (UFSCar - São Carlos) e do Observatório das Desigualdades / CIES - IUL (Centro de Investigação e Estudos de Sociologia do Instituto Universitário de Lisboa).

O Seminário contou com a presença do sociólogo português Dr. Renato Miguel do Carmo, assim como do pesquisador João Maricatto, da UnB. Nesta obra, porém, eles estão presentes através das menções, referências dialógicas dos autores que trazem experiências já realizadas ou em andamento de utilização de metodologias nessa nova interface, a qual tem recebido diferentes nomes como Humanidades Digitais, Ciência das Redes, Sociologia Digital ou Ciência de Dados. Nós preferimos a última denominação, Ciência de Dados. Veremos adiante essa "caixa secreta" que orienta as nossas escolhas cotidianas no texto-fala do pesquisador Dr. Dalton Martins ${ }^{2}$, maior ênfase acerca dessa aproximação entre as Ciências Humanas e a necessidade de um debate público sobre a construção dos algoritmos.

Então, talvez seja agora, o momento de começarmos a tratar de alguns desconfortos da aproximação entre as Ciências de Dados e as Ciências Humanas. Historicamente, as Ciências Humanas têm colaborado para a construção da sociedade, não apenas pela compreensão e análise dos contextos e relações humanas, mas pela contribuição para elaboração de dispositivos de melhoria desses contextos e relações. Desde que diversas disciplinas dessa área - a exemplo da Sociologia, Psicologia, Comunicação, Linguística e Antropologia - passaram a se debruçar mais fortemente sobre as questões das desigualdades e suas relações com direitos de minorias, suas contribuições tornaram-se fundamentais para a construção de indicativos de políticas públicas que atendam a essas minorias, de modo a torná-las visíveis.

Não obstante, no contexto atual da sociedade brasileira, vê-se reacender o debate sobre a não pertinência dessas ciências, justamente por serem elas as que causam incômodo ao descortinar os problemas estruturais da situação atual do Brasil. E agrava-se mais quando as análises re-

\footnotetext{
${ }^{2}$ MARTINS, D. O desafio da humanização dos algorítimos - Dalton Martins. 2018. (1h33m06s). Youtube. Disponível em < https://www.youtube.com/watch? $\mathrm{v}=\mathrm{WZnchhKx} 7 \mathrm{k} 4>$ Acesso em: 10 out. 2020.
} 
velam cenários de crises profundas, no âmbito social, político, econômico e na saúde; identificando coisas que deveriam ser insuportáveis, um dos principais desafios dos séculos XX e XXI: o abismo de desigualdades, em condições humanas, entre ricos e pobres, por exemplo.

Por ocasião do Seminário, no contexto da criação das falas-textos que vieram a público, os/as autores/ras viram-se diante da iminência de uma drástica mudança da governança nacional. Textos-falas escritos no âmbito de uma transição no plano político - de um governo de esquerda, o Partido dos Trabalhadores (PT), para um de centro, o Movimento Democrático Brasileiro (MDB). Naquela ocasião, já se anunciava o temor da assunção de uma retomada de ideias e práticas sob inspirações fascistas. A palavra (im)pertinente, porém, esteve muito presente nos discursos que serviram de conteúdo para as reflexões do pesquisador Márcio Antônio Gatti e da pesquisadora Luciana Salazar Salgado. Estávamos vivendo um marco na história do mundo democrático brasileiro após o traumático e despótico processo de impeachment da Presidenta Dilma Rousseff, do Partido dos Trabalhadores.

O texto da socióloga Kelen Cristina Leite ${ }^{3}$ vem nessa direção de abordagem, já que retoma e reatualiza a perspectiva marxista sobre a acumulação de capital concentrado nas mãos de poucos, consequentemente conduzindo à concentração de renda e de riqueza para alguns. A fala-texto da pesquisadora questiona a ilusão liberal acerca da acumulação de capital juntamente com o desenvolvimento tecnológico e científico enquanto onda capaz de impulsionar todos (os pobres) ao patamar do tão ambicionado desenvolvimento (ou será ao "progresso"?). A pesquisadora traz vários questionamentos em torno das desigualdades, das políticas e do papel da ciência em perspectiva interdisciplinar e multidimensional, retomando a fala de Renato Miguel do Carmo a partir dos indicadores do Observatório das Desigualdades de Lisboa, para abordar essas questões. Além disso, reflete sobre o lugar político-científico da universidade pública na ampliação das pesquisas e necessidade de seu financiamento público em tempos de polarização política radical.

\footnotetext{
${ }^{3}$ LEITE, K. Desigualdade e Políticas: O Papel da Ciência - Kelen Leite. 2018. (48m11s). Youtube. Disponível em: <https://www.youtube.com/watch?v $=$ C76b0V-

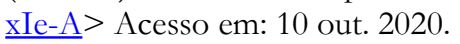


Deverá a ciência sempre dar respostas? A ciência é certeza? Acalmemos os sentidos, é preciso respirar, nos dirá a pesquisadora Viviane Melo de Mendonça. Em seu texto, Viviane parte da memória e, na escrita analítica e sensível, fundamenta ausências a partir da escrita de cura na teoria. Seu texto nos fala sobre a relação entre a potência da memória e o sufocamento político-social do mundo contemporâneo a partir do campo dos estudos (neo)materialistas e feministas sobre respiração, embora ainda de modo inicial e breve, diz a autora, acompanhando sua escrita do canto de Maria Bethânia e da arte de Adriana Varejão, emoldurada pelo YouTube e a linha do tempo do Twitter.

Essa urgência de buscar um outro mundo possível e respirável, encontra eco no texto-fala de Dalton Martins " $\mathrm{O}$ desafio da humanização dos algoritmos: formações tecnológicas da sociabilidade contemporânea", que introduz no debate conceitos como "discriminação algorítmica" e a necessidade de bases de dados para treinamento dos algoritmos que sejam inclusivas e debatidas publicamente. A reprodução de preconceitos e estereótipos pelos algoritmos do Facebook e do Google no mundo da pós-verdade e das fake-news exigem novas metodologias e conceitos interdisciplinares para ampliação do debate político em torno das decisões algorítmicas que nos afetam o cotidiano política e cientificamente.

Para não dizer que o livrinho não fala de humor nem que seja com interrogação contemporânea entre discursos "mortadela" e "coxinhas", Márcio Gatti ${ }^{5}$ retoma o debate público presente em comentários ao vídeo "Delação" do canal "Porta dos Fundos" do YouTube. Recorrendo aos conceitos da Análise do discurso de intercompreensão generalizada, analisa a polarização política produzida no polêmico vídeo de humor e a impossibilidade de uma compreensão. No "diálogo de surdos", só há espaço para uma "coexistência no dissenso".

Essa coexistência e pluralidade de discursos é da ordem da democracia e da cultura no plural. Luciana Salazar Salgado termina os limi-

${ }^{4}$ MARTINS, D. O desafio da humanização dos algorítimos - Dalton Martins. 2018. (1h33m06s). Youtube. Disponível em: <https://www.youtube.com/watch? $\mathrm{v}=$ WZnchhKx7k4>. Acesso em: 10 out. 2020.

${ }^{5}$ GATTI, M. Discursos e culturas digitais. 2018. (23m27s). Youtube. Disponível em: <https://www.youtube.com/watch?v=rLojBNiip50 > . Acesso em: 10 out. 2020. 
tes deste livrinho com mais uma potente reflexão sobre a produção de sentidos, interações, intercompreensão, pelos dispositivos digitais e sua relação com a instituição discursiva. A partir de uma apropriação não consentida do poema Viva V $a_{i a^{6}}$ de Augusto de Campos por uma reportagem do jornal Folha de S. Paulo acompanha a proliferação de invenções e de novos sentidos em espaços circunscritos a diferentes dispositivos digitais, reverberando questões de autoria, objeto poético, ética e política.

Todos os textos-fala e debates sobre metodologia de pesquisa e interdisciplinaridade, aqui reunidos, são parte de um projeto de construção de um mestrado interdisciplinar em Estudos da Condição Humana, que foi aprovado em 2019 e que continua na grande área da "Condição Humana na Contemporaneidade" e em duas linhas de pesquisa, "Sujeitos de discurso, narrativas e mobilidades" e "Desigualdades e Diferenças no Contemporâneo", nas pesquisas de sua primeira turma de mestrandas(os).

Se é certo que vamos fazendo a história através de sucessivos impactos, por vezes, violentos, tal como a sucessão de catástrofes que nos legou o período do nazismo, a contemporaneidade nos confronta com os fortes choques desencadeados pela pandemia do novo coronavírus, dentre outros. Dos muitos sentimentos que tal experiência nos causa, da perplexidade à ansiedade pela urgência de uma solução para que possamos nos ver menos vulneráveis às causas da doença (COVID-19); da percepção de que estamos impotentes querendo se desvencilhar da responsabilidade para com aqueles que coabitam o mundo, permanecendo na indiferença; aprendendo a estar morto, no dizer de Palomar de Ítalo Calvino, ou, talvez, mais interconectados, mais interdependentes e atentos a aprender a estarmos vivos e respirando...

\section{Geraldo Tadeu Soura Teresa Mary Pires de Castro Melo Vanda Aparecida Silva}

\footnotetext{
${ }^{6}$ CAMPOS, A. dos. Viva vaia: poesia 1949-1979. São Paulo: Ateliê Editorial, 2014.

${ }^{7}$ As duas edições do Seminário Ciência, Políticas e Metodologias de Pesquisa: diálogos Brasil e Portugal estão disponíveis em $<\underline{\text { https: / / seminariocienciapoliticameto- }}$ dologia.wordpress.com/>. Acesso em: 10 out. 2020.
} 
